\title{
UNILATERAL LUNG HYPOPLASIA PRESENTING IN ADOLESCENCE: A CASE REPORT
}

Kavita Paul ${ }^{1}$, Aman Bharti², Harbans Lal Kazal ${ }^{3}$

HOW TO CITE THIS ARTICLE:

Kavita Paul, Aman Bharti, Harbans Lal Kazal. "Unilateral Lung Hypoplasia Presenting in Adolescence: A Case Report". Journal of Evolution of Medical and Dental Sciences 2015; Vol. 4, Issue 56, July 13; Page: 9842-9845, DOI: $10.14260 /$ jemds/2015/1421

ABSTRACT: Pulmonary hypoplasia is a rare congenital anomaly, which is frequently associated with other congenital anomalies. Most patients have recurrent episodes of wheezing or pneumonia and severe respiratory distress leading to chronic respiratory failure whereas some may be asymptomatic. Although it is usually diagnosed in infancy and childhood, some cases do not show any symptoms until the adolescent ages. In adolescents and adults with unilateral hypolucent lung, pulmonary hypoplasia should always be kept in mind.

KEYWORDS: Lung, Unilateral, Hypoplasia, Adolescent.

INTRODUCTION: Unilateral primary pulmonary hypoplasia is rare in adulthood. Although its exact prevalence is not well known, it is estimated to be seen in about 1-2 out of every 12, 000 births. The developmental anomalies of the lung at the 4th and 24th gestational weeks may cause bronchopulmonary foregut abnormalities. It is usually present in neonatal period or in early childhood and is characterized by a decreased number of bronchial segmentation and decreased/absent alveolar air space. It usually presents with severe respiratory distress or repeated pulmonary infections and wheezing, but few cases may be asymptomatic. In this article, we report a patient with unilateral pulmonary hypoplasia, who remained asymptomatic till adolescence.

CASE REPORT: A 21 years female, presented to medicine outdoor department of G. G. S. M. C \& H, Faridkot with chief complaint of dyspnea since 4 months. Patient complained of dyspnea on climbing stairs and at more than routine activities. There was no history of fever, cough or expectoration. General physical examination was normal. Examination of respiratory system revealed smaller left hemithorax. Trachea was shifted to left side. Chest movements were diminished on left side and percussion note was dull over the left hemithorax. On auscultation, air entry was diminished on left side with few crepitations. Other Systemic examination was normal.

Routine investigations showed $\mathrm{Hb}=11 \mathrm{gm} / \mathrm{dl}, \mathrm{TLC}=6000 / \mathrm{mm},{ }^{3}$ Platelet count $=2.2 \mathrm{lakh} / \mathrm{mm}^{3}$ with ESR $10 \mathrm{~mm}$ in first hour. Liver function tests and renal function tests were normal. Sputum examination for Acid Fast Bacilli was negative two times.

Chest roentgenogram showed a left sided massive homogeneous opacity with shift of trachea to left and overinflated right lung (Figure 1). CT Scan Thorax revealed marked asymmetry in thorax. The right lung showed evidence of oligaemia suggesting compensatory over inflation. The left sided lung showed severe decrease in volume with only minimal residual lung tissue. Bronchiectatic changes were seen in this lung tissue. The mediastinum was seen to be shifted to left side (Figure 2). So a diagnosis of left lung hypoplasia was made and the patient was managed conservatively and advised regular follow up. 


\section{CASE REPORT}

DISCUSSION: Unilateral pulmonary hypoplasia is a rare condition most often acquired in early childhood, as a consequence of repeated inflammatory or infectious insults to the lungs or may be a congenital anomaly. Most patients are newborns and infants. ${ }^{1}$ However, it is usually associated with other anomalies. Both genders are affected almost equally. ${ }^{2}$

The difference between pulmonary agenesis and pulmonary hypoplasia needs to be distinguished. There is no main bronchus, pulmonary vessels and lung tissue in complete absence of lung. However, in pulmonary hypoplasia, there is underdeveloped lung parenchyma, pulmonary vessels and rudimentary bronchus and it may occur between the $4^{\text {th }}$ and $24^{\text {th }}$ gestational week. It can be categorized into two forms: primary and secondary. Most cases are usually secondary to conditions that limit fetal lung growth whereas primary pulmonary hypoplasia is rare and it is thought to be caused by an embryologic defect of the lung or vascular tissues or an in utero vascular accident. $^{3}$

Clinical findings depend on degree of pulmonary abnormality and presence of other congenital malformations. Adults may present with repeated pulmonary infections and wheezing or may be asymptomatic and diagnosed incidentally. Physical examination characteristically reveals asymmetry of two sides of thorax, reduction in respiratory movements and absence of air entry in the affected side. Diagnosis may be established with help of chest x-ray, CT thorax, fiber optic bronchoscopy and if possible pulmonary angiography and bronchography.4,5 Thomas et al. suggested that CT is more useful than bronchography in assessing the hypoplastic lung, especially for the purposes of its surgical removal. ${ }^{6}$

Radiographic findings in cases of hypoplasia are similar and characterized principally by almost total absence of aerated lung in one hemi thorax. The markedly reduced volume is indicated by approximation of ribs, elevation of ipsilateral diaphagram and shift of the mediastinum. In most cases the contralateral lung is greatly over inflated and displaced along with anterior mediastinum into the involved hemi thorax; this displacement of air containing lung to the side of involved lung may lead to some confusion in diagnosis.

CT scan may be required to establish the degree of under development and to differentiate hypoplasia from other conditions that may closely mimic it radiographically: atelectasis from other causes, severe bronchiectasis with collapse and advanced fibrothorax. Main differential diagnosis of hypoplastic lung is Swyer James syndrome. Swyer James syndrome is an uncommon abnormality characterized radiologically by hyperlucent lobe or lung and functionally by air trapping during expiration. There is substantial evidence that the syndrome is initiated by viral bronchiolitis. Although both conditions are associated with unilateral very low volume, patients with Swyer James syndrome characteristically demonstrate an air trapping on radiographs or HRCT scans performed at the end of maximal expiration. ${ }^{7}$

Treatment in adults consists of control of recurrent infections, symptomatic treatment in form of expectorants and bronchodilators and management of other complications. Prophylaxis for respiratory syncytial virus, pneumococcus and influenza infections are recommended.

CONCLUSION: Hypoplasia of lung must be considered in the differential diagnosis in the case of an opaque hemithorax. It is important to investigate the coexistence of this anomaly. Asymptomatic cases do not require any treatment if there are no additional anomalies, but these cases carry highrisk in any surgery because of low respiratory reserve. 


\section{CASE REPORT}

\section{REFERENCES:}

1. Kurkcuoglu IC, Eroglu A, Karaoglanoglu N, Polat P. Pulmonary hypoplasia in a 52-year-old woman. Ann. Thorac. Surg. 2005; 79: 689-691.

2. Ootaki Y, Yamaguchi M, Oshima Y, Yoshimura N, Oka S. Pulmonary agenesis with interrupted aortic arch. Ann. Thorac. Surg. 2001; 72: 1742-1744.

3. Porter H. Pulmonary hypoplasia. Arch Dis Child Fetal Neonatal Ed 1999; 81(1):81F-83F.

4. Borja AR, Ransdell HT, Villa S. Congenital developmental arrest of lung. Am Thoracic Surg 1970; 10: 317.

5. Landings BH. Cong malformations and genetic disorders of respiratory tract (larynx, trachea, bronchi and lungs) state of art: Am Rev Resp Dis 1979; 120: 151.

6. Thomas RJ, Lathif HC, Sen S, Zachariah N, Chacko J. Varied presentations of unilateral lung hypoplasia and agenesis: a report of four cases. Pediatr. Surg. Int. 1998; 14: 94-95.

7. Page DV, Stocker JT: Anomalies associated with pulmonary hypoplasia. Am Rev Resp Dis. 1982; 125: 216.

Figure 1: Showing Left lung hypoplasia.

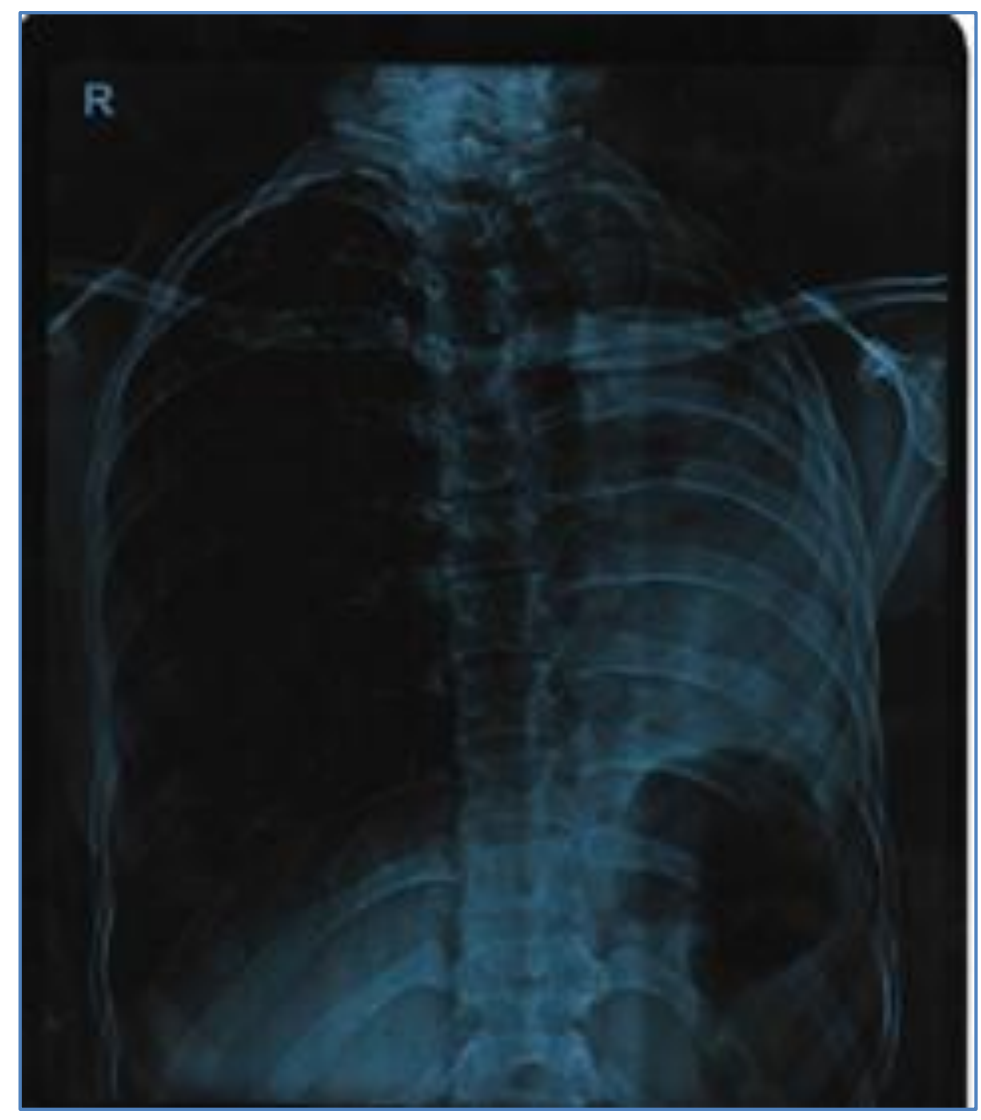

Figure 1 


\section{CASE REPORT}

Figure 2: Shows CECT Chest with left lung hypoplasia and compensatory over inflation of right lung.

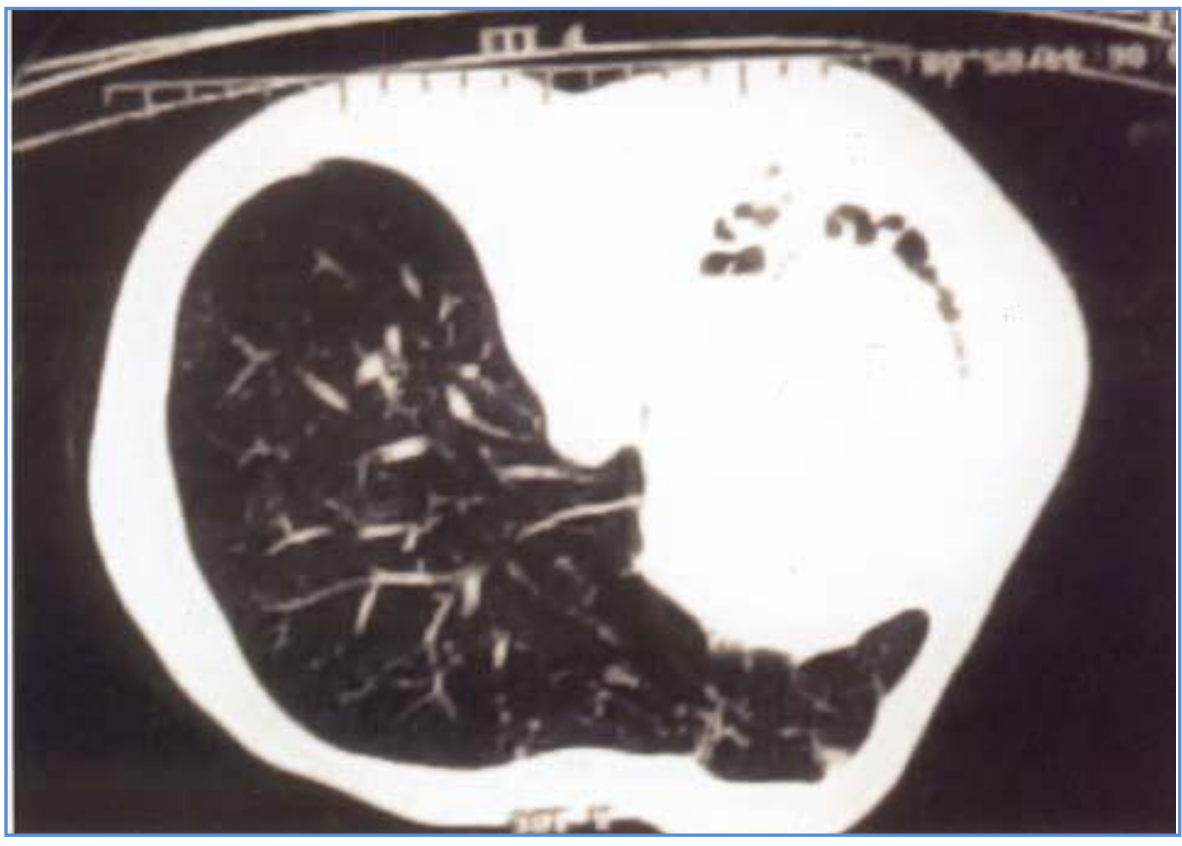

Figure 2

\section{AUTHORS:}

1. Kavita Paul

2. Aman Bharti

3. Harbans Lal Kazal

\section{PARTICULARS OF CONTRIBUTORS:}

1. Assistant Professor, Department of Medicine, GGS Medical College \& Hospital, Faridkot.

2. Senior Resident, Department of Medicine, GGS Medical College \& Hospital, Faridkot.

3. Professor, Department of Medicine, GGS Medical College \& Hospital, Faridkot.

\section{NAME ADDRESS EMAIL ID OF THE} CORRESPONDING AUTHOR:

Dr. Kavita Paul,

Department of Medicine,

GGS Medical College \& Hospital,

Faridkot-151203, Punjab, India.

E-mail: kavitapaul83@gmail.com

Date of Submission: 18/05/2015.

Date of Peer Review: 19/05/2015.

Date of Acceptance: 04/07/2015.

Date of Publishing: 13/07/2015. 